\title{
A cross sectional study to estimate the psychological stress level in medical students during Covid-19 pandemic
}

\author{
Naaz A. ${ }^{\text {* }}$, Saad M. ${ }^{2}$ \\ DOI: https://doi.org/10.17511/ijphr.2021.i01.01 \\ 1* Alia Naaz, 3rd year MBBS, Dr. Y S Parmar Medical College, Sirmaur, Himachal Pradesh, India. \\ 2 Mohammad Saad, Student, Sharda university, India.
}

Introduction: Stress and anxiety have been a common topic of discussion among the medical students in normal circumstances owing to the burden of immense studies, clinical rotations, regular exams and assessments. Material and methods: A cross sectional study consisting of 330 medical students studying in various medical colleges in various states like Himachal, Karnataka, Haryana, Rajasthan, Bihar, Punjab, Delhi etc. was conducted using online forms that were shared in various WhatsApp college groups. The questionnaire was a simple 10 question form consisting of the Kessler's psychological distress scale questions. The stress levels were defined according to the Kessler's psychological distress scale k10. Results: The results of the study showed that $72.5 \%$ of total participants suffered from mild to moderate levels of stress with $20.6 \%$ students suffering from mild stress, $15.5 \%$ from moderate stress and significant $36.4 \%$ from severe stress. Similarly, various socio-demographic determinants have also been studied for any relation to these high stress levels. The treatment seeking behaviour among medical students also reflected poorly when it came to seeking help from health professionals. Conclusion: It was found that during the covid-19 lockdown, medical students suffered from severe stress levels which is a topic of concern for the authorities and calls for a timely intervention to control the situation. The treatment seeking behaviour is also a topic of concern as medical students being most exposed to the knowledge of mental health do not themselves prefer to take treatment from a health professional.

Keywords: Covid-19 pandemic, Lockdown, Psychological stress, Kessler psychological distress scale (k10), Medical students

Corresponding Author

Alia Naaz, 3rd year MBBS, Dr. Y S Parmar Medical College, Sirmaur, Himachal Pradesh, India. Email: thealianaaz@gmail.com
How to Cite this Article

To Browse

Naaz A, Saad M, A cross sectional study to estimate the psychological stress level in medical students during Covid-19 pandemic. Public Health Rev Int J Public Health Res. 2021;8(1):01-06.

Available From

https://publichealth.medresearch.in/index.php/ijphr/ article/view/153

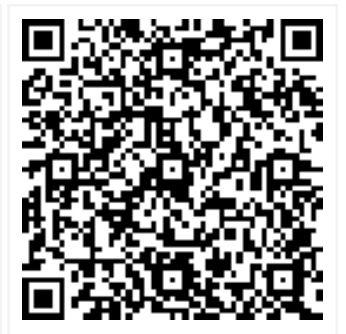

Manuscript Received 2021-01-25

Conflict of Interest No

Review Round 1
2021-02-05
Funding
Nil

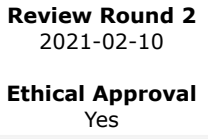

Review Round 3

Plagiarism X-checker $4 \%$
Accepted 2021-02-15

Note 


\section{Introduction}

The covid pandemic which started in December in Wuhan China has spread to almost all parts of the world causing great concerns all over the world. With no medicine or vaccine available for Covid-19, the situation has turned worrisome and source of stress for everyone. More than a third of the world's population had been put under lockdown with restricted movements to contain the spread of the virus. People have been strictly advised to maintain social distance, wear a mask, and sanitize their hands frequently.

India, the second most populous country is no different from the rest of the world when it came to lockdown and almost 135 crore people were restricted to their homes. For us Indians, challenges in the medical sector, further deepens the worries that heighten psychological distress. The lack of adequate medical facilities to all, cost of treatment and increasing deaths have been the primary source of concern to everyone.

In times of an epidemic the fear of getting infected with the virus/disease, people tend to experience anxiety, stress depression etc.

Stress can be explained as a feeling of emotional and physical tension which arises from any event that threatens our homeostasis [1]. On the other hand, the fear of the unknown is termed as anxiety, that is the body's natural response to stress. Depression is viewed as a state of disinterest that affects daily activities. It is surmised that people facing a pandemic with no vaccination or treatment would result in fear of the unknown (in this case, the coronavirus) making them anxious, stressed and depressed.

Keeping in mind the concerns regarding psychological distress raised around the globe, Xiang et al [2] have argued for a timely action on mental health during the Covid-19 pandemic. Furthermore, the World Health Organization [3] has also issued public interest guidelines to address psychological issues that may arise.

As these may be seen in common people, medical students may have been at a greater risk of developing stress and anxiety owing to the change in routine, lack of social interactions and burden of studies. Staying at home has caused a lot of challenges in academics for the students and teachers alike.
More so, not being able to attend the clinical rotations and getting hands-on practice of the cases has caused a lot of stress as most students worry about not being competent enough due to lack of exposure to clinical cases. Due to the nonavailability of logistical support for online teaching in their homes, some are deprived of the privilege of online teaching. Most of the students are not able to grasp and understand a lot of topics being covered through various online platforms. Many of the students feel that they will lag behind in the knowledge of the course. All these have been a cause of stress and anxiety among most students. Therefore, this study was planned to identify and analyse the stress levels of medical students across India and to explore its relation to the socio demographic profile of the students along with finding out the treatment seeking behavior of medical students when it comes to mental health.

\section{Objectives}

\section{Primary Objective:}

- To estimate the level of psychological stress in medical students during Covid-19 pandemic

\section{Secondary Objective:}

- To find out the relationship between stress and various socio-demographic determinants.

- To study the treatment seeking behaviour among medical students.

\section{Method}

\section{Study design}

A cross sectional study was conducted among students studying in medical colleges across the country.

The questionnaire was conducted using Google Forms and a request to participate in the study was sent to all students through WhatsApp groups.

\section{Study population}

The study population consisted of medical students in various colleges enrolled in mbbs/bds courses across the country. Total of 330 students voluntarily filled out the questionnaire, the identity of the individuals remained anonymous.

Questions based on:

The questions included in the form were all the 10 questions that constitute the Kessler psychological distress scale. 
The Kessler Psychological Distress Scale (K10) [4] is designed to measure anxiety and depression through a 10-item questionnaire. Each question pertains to an emotional state and each has a fivelevel response scale. This instrument uses a consumer self-report measure making it a desirable method of assessment.

The options for choice were as below for each question asked above:

All of the time (score 5)

Most of the time (score 4)

Some of the time (score 3 )

A little of the time (score 2)

None of the time (score 1 )

\section{Scoring/ statistical analysis}

Each item was scored from one 'none of the time' to five 'all of the time'. Scores of the 10 items were then summed, yielding a minimum score of 10 and a maximum score of 50 . Low scores indicate low levels of psychological distress and high scores indicate high levels of psychological distress.

\section{Interpretation of scores}

The 2001 Victorian Population Health Survey [5] adopted a set of cut-off scores that may be used as a guide for screening for psychological distress. The cut off score for classifying psychological stress level is detailed below.

K10 Score: Likelihood of having a mental disorder (psychological distress)

10 - 19 Likely to be well

20 - 24 Likely to have a mild disorder

25 - 29 Likely to have a moderate disorder

30 - 50 Likely to have a severe disorder

\section{Results}

In the research conducted a total of 330 students participated out of which 98 were males and 232 females. The students participated from various states across India, with maximum participation from Himachal Pradesh (38\%) followed by Haryana (21\%), Karnataka (19\%), Chandigarh, Punjab, Delhi and other states. (Table no.1.e)

Table-1: Socio-demographic characteristics of participants

\begin{tabular}{|c|c|c|}
\hline Characteristics & \begin{tabular}{|l|} 
No. \\
\end{tabular} & Percentage \\
\hline \multicolumn{3}{|l|}{ Gender } \\
\hline Male & 98 & 29.8 \\
\hline Female & 232 & 70.2 \\
\hline Total & 330 & \\
\hline \multicolumn{3}{|l|}{ Area } \\
\hline Rural & 120 & 36.5 \\
\hline Urban & 210 & 63.5 \\
\hline \multicolumn{3}{|l|}{ Family } \\
\hline Nuclear & 220 & 66.5 \\
\hline Joint & 110 & 33.4 \\
\hline Total & 330 & \\
\hline \multicolumn{3}{|l|}{ Profession } \\
\hline 1st Prof & 40 & 12.1 \\
\hline 2nd Prof & 108 & 32.8 \\
\hline Final Prof & 179 & 54.1 \\
\hline Intern & 3 & 0.9 \\
\hline \multicolumn{3}{|l|}{ State wise participation } \\
\hline Himachal Pradesh & 128 & 38.9 \\
\hline Chandigarh & 20 & 6 \\
\hline Haryana & 70 & 21.2 \\
\hline Karnataka & 64 & 19.4 \\
\hline Punjab & 16 & 4.8 \\
\hline Delhi & 11 & 3.3 \\
\hline $\begin{array}{l}\text { Others (Bihar, up, Andra, Gujarat, Tamil Nadu, Kerala, } \\
\text { Rajasthan) }\end{array}$ & 20 & 6 \\
\hline Total & 330 & \\
\hline
\end{tabular}

When the overall stress levels of all the students were estimated the results were as follows: $27.3 \%$ were likely to be well, $20.6 \%$ were likely to be under mild stress, $15.5 \%$ under moderate and a significant percentage of 36.4 were under severe stress.

Table-2: Proportion of students with different levels of stress

\begin{tabular}{|l|l|l|}
\hline \multicolumn{1}{|c|}{ Stress level } & \multicolumn{1}{c|}{ No. } & \multicolumn{2}{c|}{ Percentage } \\
\hline Well & 90 & 27.35 \\
\hline Mild & 68 & 20.66 \\
\hline Moderate & 51 & 15.5 \\
\hline Severe & 120 & 36.4 \\
\hline
\end{tabular}

Table-3: Relationship between stress levels and socio-demographic variables

\begin{tabular}{|c|c|c|c|c|}
\hline $\begin{array}{c}\text { Socio-demographic } \\
\text { variable }\end{array}$ & $\begin{array}{l}\text { No of } \\
\text { student }\end{array}$ & Mild & Moderate & Severe \\
\hline \multicolumn{5}{|l|}{ Gender } \\
\hline Male & 98 & $\mid \begin{array}{l}16 \\
(16.32 \%)\end{array}$ & $\begin{array}{l}19 \\
(19.38 \%)\end{array}$ & $\begin{array}{l}38 \\
38.77 \%\end{array}$ \\
\hline Female & 231 & 52 22.5\% & 32 13.8\% & $\begin{array}{l}82 \\
35.49 \%\end{array}$ \\
\hline & & & & \\
\hline
\end{tabular}




\begin{tabular}{|l|l|l|l|l|}
\hline Rural & 120 & $24(20 \%)$ & $15(12 \%)$ & $45(37 \%)$ \\
\hline Urban & 210 & $44(20 \%)$ & $36(17 \%)$ & $75(35 \%)$ \\
\hline Family type \\
\hline Nuclear & 220 & $42(19 \%)$ & $31(14 \%)$ & $82(37 \%)$ \\
\hline Joint & 110 & $26(23 \%)$ & $20(18 \%)$ & $38(34 \%)$ \\
\hline Professional year \\
\hline 1st Prof & 40 & $10(25 \%)$ & $10(25 \%)$ & $15(37 \%)$ \\
\hline 2nd Prof & 108 & $30(27 \%)$ & $15(13 \%)$ & $36(33 \%)$ \\
\hline Final Prof & 179 & $28(15 \%)$ & $26(14 \%)$ & $67(37 \%)$ \\
\hline
\end{tabular}

When the stress levels were observed for males and females individually, it was seen that $16 \%$ males were under mild stress, $19 \%$ under moderate stress and $38 \%$ under severe stress. Among females, $22 \%$ were under mild stress, $13 \%$ were moderate stress and a $35 \%$ under severe stress. This data shows the maximum proportion of males and females suffered from severe stress during the lockdown.

Relations between the area that the students reside in were also taken into consideration while associating the level of stress and it was found that among the students living in rural areas $20 \%$ suffered from mild stress, $12 \%$ from moderate stress, and $37 \%$ from severe stress. Among students living in urban areas, 20\% suffered from mild stress, $17 \%$ from moderate and $35 \%$ suffered from severe stress. Thus the comparative data between rural and urban doesnt show a significant difference and hence we can conclude that the stress levels were similar irrespective of the place of residence of the students( urban or rural).

Relation between the stress levels and type family was also calculated and found among students living in a nuclear family $19 \%$ suffered from mild stress, $14 \%$ from moderate and $37 \%$ suffered from severe stress and students living in a joint family showed that $23 \%$ suffered from mild stress, $18 \%$ moderate stress, $34 \%$ from severe stress.

Similarly, an association between the professional year and stress levels were observed and found that $37 \%$ students in first year suffered from severe stress, 33\% students in second year and $37 \%$ students in final prof suffered from severe stress levels. Thus we can clearly see that there is not much difference among the stress levels and the year that the student is studying is as they experienced almost equal levels of stress irrespective of the year.

Mental health and issues are more often than not ignored by common people and are not considered illness by many. This view is mainly due to lack of knowledge in the subject of mental health.
When it comes to medical students, they get alot of exposure and knowledge related to mental health and illness and have easy accessibility to health professionals for concerned issues. However, it is observed that even medical students who have more knowledge than a common man, fail to follow it and prefer not to visit a health professional. It is surprising to see that even though $72.5 \%$ of students suffered from mild to severe levels of stress. About $69.6 \%$ believed they didn't require any help. The ones who were aware of the problem turned to their friends for help (59\%), 27\% took help from parents while only $7 \%$ seeked help from a health professional and $7 \%$ from other sources. Apart from the ones suffered, a general perception of medical students was also checked and was found $44 \%$ students would seek help from friends if they ever require help, 33\% from parents and $15 \%$ from a health professional.

Table-4: Health seeking behaviour - Perception and practice.

\begin{tabular}{|c|c|c|c|c|}
\hline \multirow[t]{2}{*}{ Source } & \multicolumn{2}{|c|}{$\begin{array}{l}\text { Perception for } \\
\text { Source of help if } \\
\text { ever need it }\end{array}$} & \multicolumn{2}{|c|}{$\begin{array}{c}\text { Source of help actually sought in } \\
\text { students suffering from mild- } \\
\text { moderate stress }\end{array}$} \\
\hline & No. & Percentage & No. & Percentage \\
\hline Parents & 112 & $33 \%$ & 27 & $27 \%$ \\
\hline Friends & 148 & $44 \%$ & 59 & $59 \%$ \\
\hline $\begin{array}{l}\text { Health care } \\
\text { professional }\end{array}$ & 51 & $15 \%$ & 7 & $7 \%$ \\
\hline Other sources & 19 & $8 \%$ & 7 & $7 \%$ \\
\hline
\end{tabular}

The Covid-19 pandemic and the associated lockdown to contain the spread of the diseases took a toll on the mental health of a large amount of the population including medical students. Everyone turned to different things to mentally feel better in the depressing and stressful atmosphere. According to the survey, $30 \%$ medical students preferred to talk to friends or interact socially to elevate their moods, while $28 \%$ students practiced exercise routine to stay physically as well as mentally healthy, 6\% took to Yoga and Meditation each as stress busters.

Table-5: Stress busters practiced by students

\begin{tabular}{|l|l|l|}
\hline \multicolumn{1}{|c|}{ Stress busters } & No. & Percentage \\
\hline Exercise & 95 & $28 \%$ \\
\hline Yoga & 20 & $6 \%$ \\
\hline Social interactions & 102 & $30 \%$ \\
\hline Meditation & 23 & $6 \%$ \\
\hline Haven't thought about it & 57 & $17 \%$ \\
\hline Others (dance, sleep, painting, music, art) & 3 & $0.9 \%$ \\
\hline
\end{tabular}


$17 \%$ students did not think about the issue of mental health or ways to improve it during the lockdown and seemed to be indifferent.

\section{Discussion}

The fact that more than half of the study population of students fall into the severely stressed level is alarming and calls for an intervention for an improvement. Mental health is often a neglected topic and has been since many decades. With the current lockdown and pandemic, students have been facing severe stress which is not being taken care of. The current curriculum of online classes focuses on the academic aspect only, while it is difficult for the common medical student to stay emotionally motivated due to the immense stress and anxiety as seen in the results. What may be the possible reasons and solutions to this problem is a topic that needs to be discussed in every medical college to ensure the well being of the students during such a stressful period.

Deteriorating mental condition should be of major concern to parents and teachers because without a good state of mind, students will not be able to perform up to their potential and will consecutively lag behind. Online teaching and being locked at home has caused a great amount of stress in medical students which needs to be addressed as soon as possible. Motivational sessions, regular feedbacks and reducing the burden of academics are few possible solutions into the problem, According to $C D C$, the persons who are more risk to stress are the older adults with chronic illness who are at high risk category for COVID-19, children, teens, health care workers, persons with mental health problems and substance use [6].

There are mainly four ways to cope with the stress i.e. first is taking break from news of COVID-19 which is upsetting, second is taking care of body by exercise, yoga, meditation, good sleep hours, balanced diet, avoid drugs and alcohol use, third is to activities which we are good, indoor activities, or any productive working, studying, learning and fourth is connecting with friends and family to letting out the feeling [7].

In a study done by Dangi Ravi Rai, Dewett Parul \& Joshi Pallav [8] investigators found that $73.26 \%$ participants had severe stress levels after 15 days of lockdown and when it was again assessed after 21 days of lockdown, a total of $80.86 \%$ participants were having severe stress levels.
Investigators also compared the stress level to find the difference and there was a statistically significant difference between both stress levels. So at the end investigators can say that increasing the number of days for lockdown is also increasing the stress level of the participants.

Hawryluck et al [9] conducted a study on psychological effects of quarantine, and reported that quarantined persons exhibited a high prevalence of psychological distress: posttraumatic stress disorder (28.9\%) and depression (31.2\%)

Similarly in the study done by Sultan Ayoub Meo et al [10] it was found that $125(23.5 \%)$ medical students felt disheartened and depressed. The most probable reasons for negative consequences for mental health during quarantine are that people considered it an unpleasant experience, because of having to depart from fellows, friends and family, losing the ability to move about freely, experiencing doubts about the spread of disease, and developing intense feelings and reactions. In the present study similar results were found with $36.4 \%$ medical students in India suffered from severe stress levels.

\section{Conclusion}

According to the study, $36.4 \%$ students have been severely stressed during the lockdown due to the Covid-19 pandemic.

\section{What does the study add to the existing knowledge?}

This is a topic of concern and should be looked into by the authorities so as to improve the state of mind of the medical students. A healthy mind is equally important as a healthy body and proper attention must be given in order to ensure well being of the students. The budding doctors are the future of our country, on whose hands the health system will rely in the coming years; but will they be able to serve if their own mental condition is being ignored? Today's generation is the future of our country and how we help them overcome this hurdle, is what will paint the future of the healthcare system of the country.

\section{Author's contribution}

Dr. Alia Naaz: Concept, study design

Dr. Mohammad Saad: Manuscript preparation 


\section{Reference}

01. Selye, H. The Stress of Life. McGraw-Hill, New York. 1956.

[Crossref]

02. Xiang YT, Yang Y, Li W, Zhang L, Zhang Q, Cheung $\mathrm{T}, \mathrm{Ng} \mathrm{CH}$. Timely mental health care for the 2019 novel coronavirus outbreak is urgently needed. The Lancet Psychiatry. 2020 Mar $1 ; 7(3) 228-9$.

[Crossref]

03. World Health Organisation. WHO/2019nCoV/Mental_Health/2020. 1.

[Crossref] [PubMed] [Google Scholar] [Crossref]

04. Kessler RC, Andrews G, Colpe LJ, Hiripi E, D K MR, T NORMAND SL, WALTERS EE, Zaslavsky AM. Short screening scales to monitor population prevalence and trends in non-specific psychological distress. Psychological medicine. 2002 Aug $1 ; 32(6) 959$.

[Crossref]

05. Victorian Population Health Survey. MelbourneDepartment of Human Services. Victoria. 2001. [Crossref]

06. Center for Disease Control and Prevention. Coronavirus Disease impact on Older Adults. Center for Disease Control and Prevention. 2020.

[Crossref]

07. Unicef. Coronavirus (COVID-19) parenting tips [Internet]. Unicef. 2020;1-30.

Available from: [Article] [Crossref]

08. Dangi Ravi Rai, Dewett Parul, Joshi Pallav. Stress Level and Coping Strategies Among Youth During Coronavirus Disease Lockdown in INDIA. Aegaeum Journal. 2020;8(7)605-615.

[Crossref]

09. Hawryluck L, Gold WL, Robinson S, Pogorski S, Galea S, Styra R. SARS control and psychological effects of quarantine, Toronto, Canada. Emerg Infect Dis. 2004;10(7)12061212.

[Crossref]
10. Sultan Ayoub Meo, Abdulelah Adnan Abukhalaf, Ali Abdullah Alomar, Kamran Sattar, David C Klonoff. COVID-19 Pandemic- Impact of Quarantine on Medical Students' Mental Wellbeing and Learning Behaviors. Pak J Med Sci. 2020 May;36(COVID19-S4)S43-S48. [Crossref] 